\title{
Functional Capacity Assessment in Oncogeriatric
}

\author{
Esdras Edgar Batista Pereira*, Ney Pereira Carneiro dos Santos \\ Faculty of Medicine, Federal University of Pará, Brazil \\ *Corresponding author: Esdras Edgar Batista Pereira, Faculty of Medicine, Federal University of Pará, Brazil \\ To Cite This Article: Esdras Edgar Batista Pereira. Functional Capacity Assessment in Oncogeriatric. Am J Biomed Sci \& Res. 2019 - 5(6). AJBSR. \\ MS.ID.000965. DOI: 10.34297/AJBSR.2019.05.000965.
}

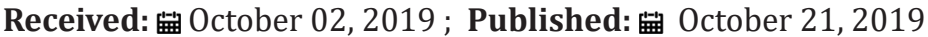

\section{Mini Review}

In the last decades, the number of elderly people in the world population has increased, a conquest of humanity, through improvements in health, education and economics, among other factors that contribute to a greater longevity $[1,2]$. The increase in the life expectancy of the population occurs together with the increase in the prevalence of chronic and degenerative diseases, which rise from 60 years, among them cancer [3,4]. According to the International Agency for Research on Cancer (IARC), the world had an incidence of about 11 million cancer cases in 2002, where $45 \%$ of cases were people 65 years of age or older. This incidence increased to 14 million in 2012 and the elderly represent $47 \%$ of these cases [5]. By 2050, projections estimate that three out of five cases of cancer will occur among the elderly [6]. This information reinforces the need for integrated action between two areas of health, oncology and geriatrics, called geriatric oncology or oncogeriatric, capable of understanding and treating the elderly oncology, taking into account their specificities [7]. This new approach evidences global functionality as a health predictor. Its identification can help in the prediction of tolerance to cancer treatment, as well as structure conducts directed to this age group [8].

Global functionality is the starting point for assessing the health of the elderly, which is measured by functional capacity, defined as the ability to manage one's own life or take care of oneself. These criteria encompass the integrated and harmonious functioning of daily life activities with functional systems such as cognition, mood, mobility and communication [9].This research includes the application of Comprehensive Geriatric Assessment, a multidimensional assessment tool where the various problems of the elderly are discovered, described and explained [10]. It is a research tool used by geriatricians and gerontologists to evaluate the general health of the elderly. It is one of the pillars of geriatric care, as part of an interdisciplinary and multidimensional diagnostic process [11-13]. The evaluation of these domains early identifies problems of a biopsychosocial nature, through scales and standardized instruments, that help in the elaboration and management of more effective, efficient and safe care plans, reducing the possible iatrogenics, which can potentiate the functional impairment of the oncological elderly [14].

With this evaluation, the so-called geriatric syndromes, which are clinical conditions involving multiple systems, can be described as common, such as cancer, despite their different presentations, such as cognitive impairment, postural instability, incontinence, immobility, etc. Therefore, knowledge of the particularities of aging is necessary for interventions that prioritize the health of the elderly with cancer $[15,16]$. Studies point to the benefits related to the evaluation of functionality in elderly care services, showing that this practice is associated with lower health spending, reduction in the number and length of hospitalizations, reduction of institutionalization, improvement of quality of life, lower frequency of polypharmacy, improvement in performance in daily life activities and reduction of mortality rates [17].The clinical parameters contained in the functional capacity assessment allow the global visualization of the oncological elderly, which in some way interfere with the quality of life of this population. The approximation between these clinical parameters makes possible the identification of remediable problems that imply in the prevention of risk factors, treatment, prognosis and rehabilitation in the health of the elderly oncology.

The instruments present in the broad geriatric evaluation have ideal characteristics for a population screening: non-invasive methodology, with relatively easy and quick and inexpensive applicability. This demonstrates its application in clinical practice in oncogeriatric. Thus, understanding the aging process broadly, considering the instruments of clinical and functional domain contained in the broad geriatric evaluation, facilitates the understanding of the determinants of health of the elderly population with cancer, having the applicability of predicting the 
health of the elderly in an interdisciplinary way, to base prevention strategies, to facilitate the management and elaboration of future care plans necessary for the elderly oncology.

\section{References}

1. United Nations (2011) Security, economic power and independence in aging. Report on the State of World Population 2011. New York: United Nations Population Fund (UNFPA).

2. World Health Organization (2012) The Demographics of Ageing. Global brief for World Health Day 2012. Genebra.

3. Hansen EO, Tavares STO, Cândido SA, Pimenta FAP, Moraes EM, et al. (2011) International classification of functionality, disease and medical prognosis in elderly patients. Rev. méd. Minas Gerais 21 (1): 55-60.

4. Campolina AG, Adami F, Santos JLF, Lebrão ML (2013) The health transition and changes in the healthy life expectancy of the elderly population: possible impacts of the prevention of chronic diseases. Reports in Public Health 29 (6): 1217-1229.

5. International Agency for Research on Cancer (IARC). World Health Organization (2013) GLOBOCAN 2012: Cancer Incidence, Mortality and Prevalence Worldwide.

6. Bray F, Moller B (2006) Predicting the future burden of cancer. Nature 6 (1): 63-74.

7. Assis CMRB, Melo HMA, Melo EMA, Kitner D, Costa Júnior JI (2011) Geriatric oncology: concepts, trends and challenges. Geriatr. Gerontol 5 (2): 106-111.

8. Cerullo FC, Ferrini G, Ciaburri A, Scambia M, Bernabei G, et al. (2011) Misure di funzione fisica in oncogeriatria. Giornale Di Gerontologia 5 (9): 265-272.
9. Moraes EN (2012) Health Care of the Elderly: Conceptual Aspects. 1 ed. Brasília (DF): Pan American Health Organization - Representation Brazil, P: 98

10. Karnakis $T$ (2011) Oncogeriatric: a review of the broad geriatric assessment in cancer patients. RBM 68(2): 8-12.

11. Ellis G, Whitehead MA, Robinson D. O'neill D, Langhorne P (2011) Comprehensive geriatric assessment for older adults admitted to hospital: meta-analysis of randomized controlled trials. British Medical Journal.

12. Parks RM, Lakshmanan R, Winterbottom L, Morgan DA, Cox K, et al. (2012) Comprehensive geriatric assessment for older women with early breast cancer - a systematic review of literature. World Journal of Surgical Oncology 88 (10): 1-9.

13. Mohile SG, Magnuson A (2013) Comprehensive Geriatric Assessment in Oncology. Interdisciplinary Topics in Gerontology Journal 38: 85-103.

14. Welsh TJ, Gordon AL, Gladman JR (2013) Comprehensive geriatric assessment - a guide for the non-specialist. International Journal of Clinical Practice, 68: 3.

15. Moraes EM, Marino MCA, Santos RR (2010) Major geriatric syndromes. Rev Med Minas Gerais 20 (1): 54-66.

16. Limpawattana P, Sawanyawisuth K, Soonpornrai S, Huangthaisong W (2011) Prevalence and recognition of geriatric syndromes in an outpatient clinic at a tertiary care hospital of Thailand. Asian Biomedicine Journal 5 (4): 493-497.

17. Nishinaga M (2007) Comprehensive Geriatric Assessment and Team Intervention. Japan Med Assoc J 50 (6): 461-466. 